\title{
Esencias del Vaticano II
}

\author{
Tomás MARCos Martínez, OSA \\ Profesor del Estudio Teológico Agustiniano
}

RESUMEN. Documentos, crónicas, comentarios, interpretaciones... Los diversos análisis sobre el pasado concilio ecuménico han ido conformando un río casi sin orillas. Habría que intentar la dirección contraria, buscar el venero, aunque suponga surcar corriente arriba. En ese caso ¿cuáles serían las aportaciones principales del Vaticano II? ¿Habría siquiera algo así como un legado central? Para llegar a buen puerto nos fiaremos de avezados pilotos de la nave teológica que ha sorteado las revueltas aguas del siglo XX (Chenu, Congar, De Lubac, Rahner, Ratzinger) y que bregaron luego en la sala de máquinas del crucero conciliar.

PALABRAS CLAVE. Renovación teológica, libertad, comunión, ecumenismo, evangelio.

ABSTRACT. Documents, reports, comments, interpretations... The various analyses of the past ecumenical council have shaped a river almost without shores. We should try the opposite direction, seek the fountain, although it supposes sailing upstream. In that case what would be the main contributions of Vatican II? Would there even something like a central legacy? To reach the goal we trust in experienced pilots of the theological ship which has weathered the troubled waters of the twentieth century (Chenu, Congar, De Lubac, Rahner, Ratzinger) and then grappled in the engine room of the conciliar cruiser.

KEYWORDS. Theological renewal, freedom, communion, ecumenism, gospel. 
Quién lo diría, parece que fue ayer, pero hace ya más de 50 años del Vaticano II. En lo personal es bastante tiempo, tanto como media vida (por pedir que no quede); pero en lo colectivo no es cronológicamente gran cosa, apenas un recodo en la historia. $Y$ sin embargo, significativamente, el concilio lo ha subvertido todo. Efectivamente, jcómo hemos cambiado! De los enigmáticos sortilegios latinos a las aclamaciones litúrgicas colectivas, del velo de nuestras madres a los letreros pidiendo recato, de las celebraciones obligadas y masivas a las presencias ralas y envejecidas, de los susurros devocionales a la concentración en la Biblia... ¿Qué nos ha ocurrido? ¿Qué sucedió en el concilio? Esquivando el vértigo de los tiempos y las modas acudamos a la solidez de los cimientos, a las razones que nos testó el Vaticano II.

\section{PREMISAS}

El concilio Vaticano II se antoja todavía inabarcable. Históricamente ha conformado un hito, un acontecimiento que decide un antes y un después, quizá "el hecho más importante del siglo XX"1; no debiera sonar tan exagerado - contraponiéndole las guerras mundiales o el progreso científico-, dado el influjo social del cristianismo y la Iglesia en el mundo. Teológicamente, ha supuesto "la gran gracia que la Iglesia ha recibido en el siglo XX", como resumió Juan Pablo II, una fuerza impetuosa y renovadora del Espíritu, un "nuevo pentecostés", según soñó Juan XXIII². Y materialmente, ha producido ingente bibliografía en crónicas del antes, durante y después del evento; actas de esquemas y documentos; y comentarios textuales e interpretaciones teológicas, lo que está lejos de acabar, pues todo rebrotará ahora con la efeméride quincuagenaria ${ }^{3}$.

1 M. FraIJó, Nuevo papa, viejas urgencias: El País, 16.III.2013, citando a Aranguren.

2 JuAN PABLO II, Novo millennio, 6.I.2001, 57; JUAN XXIII, Humanae salutis, 25.XII. $1961,21$.

3 A modo de ejemplo, el último gran estudio histórico es G. Alberigo (ed), Historia del concilio Vaticano II, I-V, Salamanca 1999-2008; se han cerrado las Acta et Documenta preparatorias y las Acta Synodalia conciliares, 53 tomos de documentación; el comentario más reciente es P. HÜNERMANN - B.J. HILBERATH (eds), Herders theologischer Kommentar zum Zweiten Vatikanischen Konzil, I-V, Friburgo 2004-2005; y ha compuesto una serie de monografías S. MADRỊGAL, Vaticano II: remembranza y actualización. Esquemas para una eclesiología, Santander 2002; Memoria del concilio. Diez evocaciones del Vaticano II, Madrid 2005; Karl Rahner y Joseph Ratzinger. Tras las huellas del concilio, Santander 2006; 
La pretensión de este artículo es abordar solamente el significado principal, digamos la esencia del Vaticano II, más allá de sus documentos y logros concretos. Ya se sabe que Aristóteles, que dio tantas vueltas a la esencia, la definió como "lo propio de cada cosa que no se da en ninguna otra"4, y que en sentido coloquial la entendemos como la base de algo, el concentrado que conforma un perfume. Para identificar dicha particularidad especial acudiremos a sus protagonistas más importantes, de nuevo la esencia: teólogos peritos del concilio contrapunteados por obispos conciliares e invitados ilustres. Con todos ellos podremos tal vez filtrar el destilado de sus esencias al cumplirse ahora las bodas de oro de la asamblea sinodal.

No parece muy difícil seleccionar una pequeña lista de los teólogos más señalados del pasado siglo que estuvieran presentes en el Vaticano II, considerando no tanto su brillantez intelectual cuanto el influjo de su teología. Hay bastante unanimidad sobre ellos: todos habrían sido pioneros leales en la renovación de la teología, todos suscitaron resquemores o entredichos en el Magisterio, pero consiguieron finalmente (como en los cuentos de hadas) que sus ideas se impusieran en los textos conciliares a través de su asesoramiento episcopal y de la directa confección de los esquemas.

Los dominicos Marie-Dominique Chenu e Yves Congar fueron los rompedores de la modernización teológica, allá por los lejanos finales de los años 30, desde su facultad de Le Saulchoir -sita en Bélgica por problemas políticos, cerca de la frontera francesa, y trasferida luego a París-, el primero pretendiendo teologizar más desde el dato revelado, el contacto con los clásicos cristianos y la apertura a los tiempos, y menos desde la especulación metafísica; y el segundo animando al ecumenismo contra la confrontación acorazada. ¡A quién se le ocurre! Enseguida fueron destituidos de cátedra o removidos de lugar, y se denominó su intento "nueva teología", con retintín, como si se les hubiera ocurrido asar la manteca. A pocos años y no muchos kilómetros de distancia, en el escolasticado jesuítico de Fourvière, en la periferia de Lyon, seguramente inconscientes de la gravedad de la escaramuza anterior, sus profesores intentaban remozar la teología realzando también el retorno a la Biblia y los Padres, el diálogo con el pensamiento moderno y la preocupación pastoral, catalizando la renovación y las críticas Henri de Lubac, que teorizaba sobre "lo sobrenatural", la gracia rastreada como deseo religioso o insatisfacción existencial, presente de ese modo en todo hombre. Le objetaron sobre todo que la "gratuidad"

Tiempo de concilio. El Vaticano II en los Diarios de Yves Congar y Henri de Lubac, Santander 2009; Unas lecciones sobre el Vaticano II y su legado, Madrid 2012.

${ }^{4}$ Metafísica $1038 \mathrm{~b}$. 
de la gracia no podía convertirse en "necesidad" de creación, uno de esos típicos enredos bizantinos de la teología, y padecerá el mismo sino de los anteriores. Tras estas sacudidas iniciales, el jesuita Karl Rahner, con una escritura muy especulativa, al borde de la abstrusión, será el mejor decantador de la incipiente nueva teología. Con un estilo netamente escolástico asentará un contenido innovador: cristianismo anónimo (=salvación fuera de la Iglesia), inspiración como canonicidad (=Dios no dicta libros, alienta escritos normativos de comunidad), institución indirecta de los sacramentos por Cristo (=los crea la Iglesia siguiendo a su maestro), serían algunas medallas prevaticanas que podríamos colgarle. Esta reinterpretación actualizada de temas clásicos le hará sospechoso a ojos ortodoxos pero también extrañamente popular, a pesar del retorcimiento de su escritura ${ }^{5}$.

En cuanto a la Jerarquía episcopal protagonista que luego haya querido evaluar el concilio, tampoco resulta muy arduo elencar lo más granado. Habría que mencionar primeramente a Joseph Ratzinger, que en cuanto profesor de teología y perito conciliar, primero, y arzobispo de Múnich y prefecto de la Congregación para la Doctrina de la Fe, después (su etapa papal queda fuera de este estudio), nos ofrece una perfecta ocasión de simbiosis de teología y Magisterio. Como teólogo ha escrito diversas síntesis sobre el concilio, y siendo prefecto publicó un análisis demoledor del posconcilio $^{6}$. A su lado hay que poner al cardenal Léon-Joseph Suenens, arzobispo de Bruselas-Malinas, inspirador de la arquitectura del concilio (las famosas Iglesia ad intra e Iglesia ad extra) con Juan XXIII al finalizar la primera sesión, y uno de los cuatro moderadores o supervisores generales durante las tres sesiones de Pablo VI; al poco de acabar el concilio escribirá precisamente sobre lo que llama en un epígrafe "la idea maestra del Vaticano II", y tras su llegada personal al final del tiempo se publicará un libro de memorias con una segunda parte de las tres que lo componen centrada en las zozobras y enrumbamiento de la barca conciliar ${ }^{7}$.

Finalmente, no está de más compulsar voces al tiempo ajenas al catolicismo y versadas en teología, para también tener en cuenta una visión más neutral o distante o distinta del significado del Vaticano II. Como una

5 Sobre todo esto, R. Gibellini, La teología del siglo XX, Santander 1998, 177ss y 239ss.

6 J. RATZINGER, El nuevo pueblo de Dios. Esquemas para una eclesiología, Barcelona 1972, 313-356; Palabra en la Iglesia, Salamanca 1976, 318-324; J. RATZINGER - V. MESSORI, Informe sobre la fe, Madrid 1985.

${ }^{7}$ L.J. SuENENS, La corresponsabilidad en la Iglesia de hoy, Bilbao 1968; Recuerdos y esperanzas, Valencia 2000. 
de las innovaciones del concilio, símbolo de su apertura ecuménica, fue abrir espacio a "observadores" cristianos no católicos, elegidos por sus respectivas confesiones, que tenían acceso a los esquemas y a las sesiones de discusión, podemos acudir a las reflexiones sinceras y agradecidas que han publicado. Nos detendremos de nuevo sólo en los más destacables, teológicamente hablando, los protestantes Karl Barth y Oscar Cullmann. Barth, uno de los grandes nombres de la dogmática del siglo XX, iniciador de la llamada teología dialéctica, fue invitado directamente por el Secretariado para la Unidad de los Cristianos a las dos últimas fases del concilio, pero estando enfermo y hospitalizado no pudo asistir; una vez repuesto no quiso perderse un contacto de primera mano con la nueva situación, y en 1966 tras el estudio concienzudo de sus documentos estuvo en Roma una semana entrevistándose con algunos protagonistas (Bea, Ottaviani, Rahner, Congar, Ratzinger...), consignando luego sus impresiones en un breve escrito 8 . Cullmann, igualmente célebre exégeta y reconocido promotor del ecumenismo, colaboró primero en una obra colectiva sobre la percepción protestante del concilio, publicada aun faltando la última sesión conciliar, y posteriormente ofreció una valoración más general sobre el mismo ${ }^{9}$.

\section{EJES}

Al poco de clausurarse el Vaticano II, incluso ya antes, el mundo teológico empezó a hervir de comentarios y valoraciones sobre lo que había sucedido, sobre lo que estaba sucediendo, sobre lo que iba a suceder en la Iglesia. Se intentaron frases lapidarias que resumieran de un golpe lo acaecido, preñado de lo que iba a venir, sintomático del lastre soltado. Cómo entender la fe, qué es la Iglesia, cuál debiera ser el comportamiento cristiano... eran las líneas maestras de un esbozo que empezaba a contornarse. Predominaban sobre todo rasgos de cambio y liberación, una sensación de encontrarse en medio de un amplio jardín, ante caminos francos a la vista. Se percibían algunas flores de particular hermosura, cuyo aroma embriagaba de sueños y esperanzas.

8 K. BARTH, Ante las puertas de san Pedro, Madrid 1971. Es más sugerente el título original en latín: Ad limina apostolorum, Zürich 1967.

9 O. CullmanN, La Biblia en el Vaticano II: G. Lindbeck (ed), El diálogo está abierto. Las tres primeras sesiones del concilio Vaticano II, Barcelona 1967, 146-162; y Vrai et faux oecuménisme. Oecuménisme après le Concile, Neuchâtel 1971. 


\section{Fe es libertad}

En plena fiebre preparatoria, un año largo antes de la inauguración del concilio, en un simposio de reflexión sobre las expectativas del evento inminente, Chenu leyó una conferencia con el título de El fin de la era constantiniana $^{10}$. Tal cosa debiera rubricar el concilio en su opinión. Es una fórmula redonda, afirma, no inventada por él sino recurrente desde diversos estamentos, tanto magisteriales como académicos. La era constantiniana ha supuesto, por decirlo chatamente, la imbricación indiscernible de la Iglesia y el Estado, de lo religioso y lo político, nacida en el siglo IV con el edicto de tolerancia del cristianismo del emperador Constantino y vigente hasta la actualidad, después de afirmarse a través del feudalismo medieval y extenderse al mundo mediante las naciones fuertes de la Modernidad. Ha tenido rasgos positivos, por supuesto, como la inserción de los principios cristianoś en los tuétanos de sociedades y mentalidades. Pero a la postre resulta disolvente para la fe: cuando "la ley hace obligatoria la virtud"11, la estropea irremediablemente, o la vuelve hipócrita; se condenará políticamente a herejes y cismáticos, o se alentarán guerras santas, contrariando la espiritualidad libre y fraterna de lo evangélico. Otras consecuencias contraindicadas serán que la racionalidad grecoromana elimina por completo el misterio espiritual, la estructuración jurídica reduce a mínimos la espontaneidad carismática, el ministerio eclesial se vuelve más bien poder que servicio, y el impulso de misión deviene más conquista que testimonio.

La conclusión de la era constantiniana, de la cristiandad, de la sociedad confundida con la religiosidad, es negativa para la Iglesia, la fe acaba cediendo ante la cultura, predomina la acomodación mundana sobre la inspiración evangélica. Por ello, hay que recuperar la idea de Iglesia como misión en vez de instalación, convicción de conciencia más que costumbrismo social, "combate por la justicia"12 más que aceptación del (des)orden establecido. Es tiempo de intimar a la decisión (libertad-responsabilidad), de proclamar fraternidad, de luchar por los valores perdidos del reino de Dios, un tesoro escondido en el evangelio constantinizado.

10 M.D. CHENU, El fin de la era constantiniana: VV AA, Un concilio para nuestro tiempo, Barcelona 1962, 43-61.

11 Ibidem 48.

12 Ibidem 61, citando a Bartolomé de las Casas. 
"Una declaración sobre la libertad religiosa aprobada en un concilio es algo tan extraordinario como un concilio ecuménico sin anatema"13. Es casi una contradicción, como un predominio sin dominio o una certeza sin imposición, un dulce sin azúcar. Pues efectivamente, más allá de todas las perplejidades, dicha declaración de libertad (Dignitatis humanae) ha sido sancionada por una vigorosa institución religiosa de 2000 años de antigüedad, que ha sobrevivido a potentes imperios y opuestos tiempos. Una institución que sabiéndose depositaria de la revelación no pretende sin embargo sólo tolerar otras creencias, la aceptación de ideas erróneas como mal menor en bien de la convivencia en una sociedad pluralista, sino también defender su misma existencia, consecuencia de la libertad.

Aparte de un primerísimo derecho humano, la libertad es un valor cristiano primordial. El lema y resumen del comienzo de la misión de Jesús es "el reino de Dios está cerca", por tanto: "convertíos, creed la buena noticia" (Mc 1,15), esto es, elegid, decidid. Así que desde su punto cero la fe cristiana es libertad. No es posible la esperanza en Dios salvador (ni la exigencia de fraternidad que conlleva) sin la convicción interna, sin la propia decisión. "Habéis sido llamados a la libertad", resume Pablo (Gal 5,13). El Espíritu Santo, el hálito que llena los corazones de los creyentes, "sopla donde quiere", refrenda Juan (Jn 3,8). La fe, la confianza en Dios, o es libre o no es nada.

"La libertad religiosa es un derecho de la dignidad humana", proclama el concilio (DH 2), de la inviolabilidad de la conciencia, que no se debe forzar ni coartar. Es también un reflejo del desbordamiento de Dios sobre cualquier estructuración religiosa, por lo que las demás religiones, aun en su imperfección, son valoradas positivamente, "destellan la verdad que a todos ilumina" (NA 2). Incluso asume a los no creyentes, que "buscan en sombras e imágenes al Dios desconocido, puesto que todos reciben de Él la vida, la inspiración y todas las cosas" (LG 16). En resumidas cuentas, "la fe es voluntaria por su propia naturaleza" (DH 10). Si la verdad es esquiva ya científicamente, mucho más lo será espiritualmente, como consignó para la posteridad un perplejo Pilato: “¿qué es la verdad?” (Jn 18,38). La abducción de la verdad, la evidencia de su absolutez, lleva al fanatismo, a poner la certeza por encima de la persona, de lo que más vale que Dios nos libre. La revelación de Dios es verdad absoluta, sí; pero por lo mismo, por divina e inaferrable, no puede ser humanamente obligatoria, sino solo autoimpuesta en la fe.

13 MadrigAL, 2012, 390s. 
De igual modo, aunque considerado desde otro ángulo, la Iglesia no puede forzar a la sociedad a seguir sus postulados, por más convencida que esté de ellos, tiene que respetar "la autonomía de la realidad terrena" (GS 36). La sociedad es libre de reglamentarse como mejor vea, de un lado, y la verdad religiosa es fe, confianza íntima, un sentimiento que no se puede decretar. Los cristianos podemos estar seguros de la perversidad del aborto o del matrimonio homosexual o de la pena de muerte; deberemos manifestar y defender nuestras posiciones, criticando y deplorando decisiones contrarias, pero en ningún caso las podemos hacer obligatorias, por más verdaderas que las sintamos. También hay que presuponer en la organización política la buena fe, la honrada búsqueda de la convivencia de mentalidades dispares, y mucho más en las sociedades democráticas, constitutivamente defensoras de la pluralidad.

En fin, todo esto es una gran declaración conciliar de principios, que redime al menos en parte los errores y horrores históricos de la Iglesia en su coacción religiosa, que cualquiera puede recordar sin mucho esfuerzo (cruzadas, quema de herejes, inquisición). El concilio ha asumido con ello uno de los más conspicuos signos de los tiempos de nuestra época: la libertad de cada persona, lo que ha costado en la larga historia humana continua "sangre, sudor y lágrimas"14, pero que por lo mismo se nos revela un anhelo inherente a la conciencia. Y libertad es libertad, que diría el otro. No se trata de indiferentismo ni relativismo religiosos, que lo mismo nos dé so que arre, sino de tolerancia: respeto por la libertad ajena -presuponiendo su responsabilidad mientras no se demuestre lo contrario-, asumir las opiniones opuestas, aunque nos parezcan profundamente equivocadas, basados en la "dignidad y libertad de los hijos de Dios" (LG 9).

Este esfuerzo conciliar por la libertad y la tolerancia, con todo su pedigrí moderno y democrático, es el que ha sufrido las peores detracciones, y tanto de parte católica como protestante. Lo cual, como reverso de la medalla, al modo del reflejo invertido de un paisaje en un lago, no deja de evocar la prioridad del anverso, la luminosidad y derechura de la imagen directa. Los mayores reparos de Cullmann al concilio, por ejemplo, se concentran en la Gaudium et spes y en la Dignitatis humanae. Reconoce que para la opinión pública o publicada son los documentos más importantes, pero justamente eso le resulta sintomático. Opina que dichos textos tienden a olvidar que el evangelio siempre será "escándalo y necedad"

14 Tricolon popularizado por Churchill durante la II Guerra Mundial (Discurso ante el parlamento británico, 13.V.1940). 
para el mundo, citando a Pablo (1Cor 1,23), como subraya desde siempre la teología protestante de la cruz, al contrario de la teología natural católica, demasiado dependiente de una filosofía analógica y racionalista que parece suplantar la revelación bíblica. No puede haber aggiornamento o modernización a cualquier precio, diluyendo la necesidad humana de redención, la poquedad del mundo fiado a sus propias fuerzas. Sería una "capitulación ante el mundo", que sobrepasa el "diálogo con el mundo"15, seguir unas consideraciones y soluciones meramente humanas, asociándose a la sabiduría de esta tierra, desconociendo el pecado del hombre y la salvación única de Cristo. Cullmann no concreta mucho más, solo advierte de que el catolicismo (apertura universal) no debe deslizarse hacia el sincretismo (secularización indiscriminada), que necesita la "concentración bíblica" del protestantismo, que le evite "conceder una importancia excesiva a los valores seculares" 16 .

Se percibe en esto una curiosa coincidencia con Ratzinger, que también recela de la Gaudium et spes como del diablo. Llevado al Vaticano II como perito del arzobispo de Colonia, Ratzinger era por entonces un joven profesor de teología en Ratisbona. Sus impresiones personales expresaban gran consonancia con la marcha renovadora de la asamblea ${ }^{17}$. Le agradaban la autonomía del concilio sobre la Curia, la recuperación de una liturgia dialogal y comunitaria, el carácter pastoral o propositivo más que impositivo de la doctrina, la estructura eclesial de colegialidad episcopal, el impulso favorable al ecumenismo... y hasta aquí hemos llegado. Es decir, estaba de acuerdo con el proceso de aggiornamento eclesial. Pero en el cuarto periodo de sesiones, justamente al debatirse la actitud de la Iglesia hacia el mundo moderno, algo colmó el vaso, parece afluir en él un resquemor creciente hacia lo que considerará inaceptables cesiones. Según él, la Gaudium et spes va a acabar siendo el texto fundamental del concilio. Es el del diálogo con la sociedad, sí, pero cree percibir ahí un exceso de entreguismo, la semilla de la disolución en el mundo, la senda de una insana secularización, "una renovación que parece ser un cristia-

15 CullmanN, 1971, 32-40. Lo mismo piensa Barth, añadiendo Nostra aetate a los documentos recelados: hay una excesiva acomodación y optimismo respecto del mundo, que puede acabar en seducción y repetir así "los errores del protestantismo" (BARTH 26; $40 \mathrm{~s} ; 57 \mathrm{~s} ; 61 \mathrm{~s})$.

16 Cullmann, 1971, 44.

17 Esta impresiones fueron dictadas en cuatro conferencias intersesionales, luego publicadas (ver MADRIGAL, 2006, 105-136). 
nismo a precios rebajados"18. Esto contaminará los anteriores avances: la apertura al mundo se convierte en mundanización, la popularización litúrgica en trivialización, el acercamiento ecuménico en irenismo, el pluralismo teológico en confusionismo. La decadencia del catolicismo tal vez no es culpa directa del concilio, aunque ciertamente sí de su mala asimilación, "de una apertura indiscriminada al mundo, de las interpretaciones demasiado positivas de un mundo agnóstico y ateo"19.

La Gaudium et spes se convierte así en el testamento final del concilio, pero testamento irónicamente en sus dos sentidos: legado final y adiós definitivo. Expresa una ingenua acogida del mundo, un excesivo optimismo sobre él, donde apertura, diálogo y colaboración son sus ideas clave, derivando en una especie de revisión del Syllabus y reconciliación con los valores de la Ilustración. Como remedio propone compensar los desmanes de la Gaudium et spes con la lectura total del concilio en sus otros documentos, cambiar el "espíritu" utópico conciliar orientado al mundo por los "textos" reales del Vaticano II; a fin de cuentas, dedicarse a la misión de la verdad revelada sin componendas, en vez de abandonar el mundo a su libertad y extravío, "proclamar simplemente el kerygma, el llamamiento que manifiesta autoritativamente al hombre la voluntad de Dios y no le pide diálogo, sino asentimiento y conversión"20.

Por si estas objeciones no fueran suficientes va a sumarse a ellas uno de los teólogos señeros de la renovación teológica. En un libro-entrevista al recién nombrado (honoríficamente) cardenal Henri de Lubac, en el contexto preparatorio del Sínodo extraordinario de obispos de 1985 para valorar el concilio y su evolución a los 20 años de su clausura, aflora levemente la percepción de los hechos del ilustre teólogo y testigo del acontecimiento 21 . En principio, piensa que el concilio ha producido buenos frutos, como la accesibilidad litúrgica, la promoción de la Escritura o la defensa de la libertad religiosa, aunque todo ello haya conllevado también exageraciones. Estrictamente hablando, dichos frutos no los considera innovaciones sino recuperación de las primeras tradiciones, sepultadas por los siglos y el éxito de la evangelización, una vuelta a las costumbres

18 RATZINGER, 1972, 337.

19 RATZINGER, 1985, 44.

20 RATZINGER, 1972,324. "Pareciera que la misión no es la cristianización del mundo, sino la liberación del mundo en su mundanidad, el reconocimiento del mundo como mundo que hay que dejar y respetar precisamente como tal" (Ibidem 349).

21 H. DE LUBAC, Diálogo sobre el Vaticano II. Recuerdos y reflexiones, Madrid 1985. 
primeras de la Iglesia olvidadas con la identificación social o la instalación. Con todo, le parece que "ha penetrado en la Iglesia un espíritu secularizador". No dilucida mucho en qué consiste esta "mundanidad intolerante", simplemente resalta "que el mundo está dañado por el pecado y el cristiano tiene que librar en él un duro combate" 22 . Concede que apertura y libertad pueden resumir el espíritu del concilio, pero de ningún modo debe ser como abdicación sino como exigencia, esto es, apertura misionera y salvífica al mundo, al que exige una respuesta libre y comprometida con el evangelio; nada de tentaciones para un mero humanismo cristiano o simple doctrina social.

\section{Iglesia es comunión}

Para Congar, la idea que más se traspiraba durante el concilio en curso era que suponía "el fin de la contrarreforma" 23 . En el diario que iba componiendo al hilo de las sucesivas jornadas lo afirma como si fuera una conciencia general entre los Padres conciliares, una evidencia común y no un descubrimiento personal. Esto implicaba que la asamblea se intuía desmontando el exceso postridentino, se veía preñada de dos macizos gemelos apuntando un parto difícil de consecuencias hasta entonces impensables: la comunión y el ecumenismo.

1. Asistir al final de la contrarreforma conllevaba el comienzo de otra eclesiología, una manera distinta de entender la Iglesia. Consumado eclesiólogo como era, esto será lo que más va a destacar Congar: "se asiste a la confrontación de dos eclesiologías"24, anota comentando el segundo periodo de sesiones. Como expresivamente indica la palabra, la contrarreforma era un estilo confeccionado contra la Reforma protestante. Un talante contrarreformista subrayaba precisamente la autoridad, ninguneada por la Reforma en favor de la sola Scriptura. Derivaba de ello una eclesiología intensamente jerárquica, lo que Congar había llamado "jerarcología". Pero ahora advertía que estaba apareciendo "una eclesiología que aún no ha sido elaborada: una eclesiología de comunión"25.

Comunión es un concepto equívoco en teología, tirando a confuso, pero es el destino de las palabras sugerentes, llenas de polivalencia. Lite-

22 Ibidem 127ss.

23 El relato en Y. Congar, Mon journal du Concile, I-II, Paris 2002; ver también MADRIGAL, 2012, 55.

24 Congar I, 523. Lo mismo en Suenens, 2000, 143.

25 CONGAR II, 115. 
ralmente communio es el sustantivo de communis, 'común' (como en griego koinonía de koinós), y engloba nociones como participación, comunidad, solidaridad. En el Nuevo Testamento quiere señalar la 'unión espiritual' con Cristo (1Cor 1,9), manifestada especialmente en la 'participación' eucarística (1Cor 10,16), que provoca la 'unión profunda' entre cristianos (2Cor 13,13), lo cual les hace 'compartir' sus bienes (2Cor 9,13). En la historia de la Iglesia se irá perdiendo la última acepción (digamos la comunista) mientras se van a mantener las otras tres, sobre todo exteriorizadas e interrelacionadas en dos, una en torno a lo eucarístico y la otra alrededor de lo comunitario. La comunión designará entonces la celebración eucarística, que está presidida por el obispo y conforma una pequeña Iglesia local (más o menos como una parroquia actual de pueblo). Y como cada Iglesia local se sabe abierta y unida a las otras Iglesias cristianas, la comunión acabará señalando también la plenitud de la Iglesia universal (y la excomunión será la pena jurídica de exclusión eclesial) ${ }^{26}$. En resumen, la comunión señala la eucaristía, que es su sentido claro y coloquial, y alude igualmente a la comunidad eclesial en general, sin mayores concreciones, lo que por sí solo ratifica la ambigüedad de partida.

Ateniéndonos al sentido eclesiológico, comunión aludiría básicamente a la 'comunidad de fe', grupo de personas aglutinado por sus creencias de modo previo a toda organización, una comunidad de estilo de vida o testimonio (creencias, valores, actitudes) más espontánea que institucional. Como toda agrupación tiene que organizarse para preservar su identidad, la Iglesia irá tendiendo a efluir normas (litúrgicas, dogmáticas, éticas, canónicas), pero como sigue marcada por su origen comunional (basado en la simple fe común) querrá integrar en su ordenamiento a todos los creyentes. Comunión implicaría así, por fin, 'corresponsabilidad', un cruce entre participar (tomar parte) y compartir (dar parte), todos los cristianos sabiéndose activos en la configuración comunitaria.

Nos interesa el significado que Congar sobreentiende con la expresión eclesiología de comunión, de la que ha comentado que está todavía por confeccionar. Porque la está contraponiendo a una anterior eclesiología jurídica o jerárquica, y por el contexto del segundo periodo de sesiones afiebrado en las discusiones sobre la colegialidad, aludiría a una eclesiología menos primacial y más episcopal, que integre el primado papal (y el poder de la Curia romana) en la colegialidad episcopal, quien realmen-

26 Sobre esto, C. O’Donnell, Comunión/Koinonía: Diccionario de eclesiología, Madrid 2001, 192-199. 
te representa a la Iglesia universal como comunión de Iglesias locales. El papado había sido exaltado como institución en el Vaticano I para contrarrestar el secularismo decimonónico. Pero así había quedado aislado de la Iglesia, como si estuviera por encima de ella y no fuera una estructura a su servicio. Sin embargo, el papa es un obispo, su primado le viene precisamente por ser obispo de Roma, no puede entenderse fuera del colegio episcopal. La eclesiología de comunión será pues primeramente una eclesiología centrada en la colegialidad episcopal, una communio hierarchica (LG 21s). Pues bien, como es sabido la colegialidad episcopal es una de las claves novedosas de la Lumen gentium (LG 22-27), a la que se atribuye primado jurídico e infalibilidad doctrinal, lo mismo que dijera el Vaticano I del papa; y de la Christus dominus, que establece instituciones comunionales como el Sínodo de obispos (CD 5), las Conferencias episcopales (CD 37s) y los consejos presbiterales (CD 27).

En segundo lugar (aunque primero ontológico), cuando se nombra la comunión sin más, o communio ecclesialis (aparte por tanto de "comunión jerárquica" y "comunión eucarística"), el concilio suele referirse a la unidad interior y exterior entre cristianos (LG 13; PO 9; SC 69), la comunión genérica, la corresponsabilidad general cristiana, esto es, que todos participan de "la dignidad y libertad de los hijos de Dios", de un lado; y del deber "del mandamiento nuevo del amor" y del testimonio para "dilatar el reino de Dios en la tierra", de otro (LG 9). De ahí la recuperación de metáforas evangélicas y patrísticas para designar a los creyentes y sus cualidades y obligaciones como "pueblo de Dios" (LG 9), "sacerdocio común" (LG 10), "sentido de la fe" (LG 12), "apostolado salvífico" (LG 33; AA 2), "celebración eclesial" (SC 26), todas ellas resonancias de la corresponsabilidad. En este caso, hablar de comunión sería hablar de democratización, lo insustituible de cada individuo y carisma en la construcción eclesial: "tenemos que apropiarnos realmente la idea fundamental del Vaticano II y hacerla realidad hasta en los repliegues más profundos de nuestro sentimiento, por así decirlo, la idea de que la Iglesia somos nosotros"27. Las fuertes resistencias de la minoría a la idea de colegialidad, en último análisis, dependían de ello, "se temía introducir en el gobierno central de la Iglesia el concepto de conciliaridad o, si se prefiere, de democracia"28.

27 K. RAHNER, La gracia como libertad. Breves aportaciones teológicas, Barcelona 1972, 237.

${ }^{28}$ F. KöNIG, Iglesia, ¿adónde vas?, Santander 1986, 30. 
Pareciera ahora que hemos acabado metiendo la zorra en el gallinero, la democracia en la Iglesia. Sin duda, el cristianismo no es una demokratía ('poder popular') sino una ekklesía ('asamblea cúltica'), no se rige por una constitución mayoritariamente aprobada sino por un evangelio revelado. Pero aunque la Iglesia no sea una democracia, bien puede democratizarse en sintonía con los tiempos. Al fin y al cabo es lo que siempre ha hecho: en torno al I milenio funcionó de modo aristocrático (los obispos como jueces de paz y príncipes feudales) sin ser una aristocracia, y en el II se estilizó monárquicamente (primacía papal copiando las monarquías absolutas) sin ser una monarquía. La aprensión de la Iglesia hacia las democracias nacientes del siglo XIX tal vez provenga de la contrapuesta concepción de autoridad: otorgada por Dios (sacramental) y eterna en la primera, delegada por el pueblo y temporal en la segunda. Percibiría entonces esta idea como un trastorno de su tramoya, una subversión. Sin embargo, hay muchas estructuras de nuestras democracias actuales inventadas precisamente por la Iglesia. Por ejemplo, arrumbada la democracia asamblearia griega, mecanismos de una democracia representativa comienzan con los concilios eclesiales, regionales primero y ecuménicos después: reuniones de representantes de todos los rincones de una zona para resolver problemas comunes, cuyas decisiones se tomaban buscando la unanimidad (o por lo menos una mayoría cualificada); las universidades, derivadas de las escuelas monásticas y catedralicias, se distinguieron por la libertad de expresión y de elección de sus cargos; las Órdenes mendicantes nacieron desde el igualitarismo fraterno: votación de las constituciones y elección de los superiores, en ambos casos de modo conjunto y revisable.

Justamente, en su librito al poco de la clausura conciliar Suenens destaca "lo que me parece la idea clave del concilio: la afirmación de la corresponsabilidad de todos los cristianos en el seno del pueblo de Dios"29. Tiempo después, recapitulando su vida al borde del tercer milenio, ratificará la misma postura: "el Vaticano II puso fin a la imagen de una Iglesia institucional y abrió la puerta a una evolución", basada en "el sentido despertado de la corresponsabilidad de los cristianos", y en que desde "el ejercicio colegial de la autoridad suprema de la Iglesia, la lógica pedirá que se revise también el perfil del obispo en la Iglesia local o del

29 SUENENS, 1968, 7. "Si se me preguntase cuál es el germen de vida más rico en consecuencias pastorales que se debe al concilio respondería sin dudarlo: el haber vuelto a descubrir al pueblo de Dios como un todo, como una totalidad, y en consecuencia la corresponsabilidad que de aquí deriva para cada uno de sus miembros" (Ibidem 27). 
sacerdote en el corazón de las comunidades" 30 . La corresponsabilidad, por tanto, delinea un desmarque transversal, debe ser concebida de forma tanto jerárquica como genérica.

Él será precisamente, en su calidad de coordinador general, el principal ejecutor práctico de dicha renovación, consiguiendo que las ideas que flotaban en el aula quedaran atrapadas en los documentos. Primeramente, en el escenario de las dos concepciones eclesiales, la de la Curia, muy escorada hacia lo institucional, y la innovadora, más centrada en lo espiritual, "se trataba de pasar de una eclesiología jurídica a una eclesiología de comunión". Presentando una aparentemente pequeña corrección, invertir el orden de los capítulos 2 (la jerarquía) y 3 (el pueblo de Dios) del primer esbozo De Ecclesia, conseguirá la "revolución copernicana", que la Iglesia sea pensada más desde lo constitutivo y común, la fe, y no tanto desde lo directivo y parcial, la jerarquía. En segundo lugar, encallada la discusión sobre la colegialidad episcopal, pues revalorizaba el episcopado en su conjunto como máxima autoridad y parecía entonces mellar la autoridad papal, Suenens ofreció a la votación de la asamblea una serie de preguntas orientativas para el decantamiento intersesional. El grupo curial protestó airadamente por "abuso de poder"-sólo a la Comisión Teológica (presidida por Ottaviani) correspondía plantear cuestiones teológicas-, pero tras "dos semanas de suspense" y los otros tres moderadores dispuestos a ceder "propter bonum pacis", una "comisión de arbitraje" de cardenales nombrada por el papa asumió por los pelos -"gracias a un cardenal distraído que levantó la mano siendo que acababa de formular reservas"- la posibilidad de dichas preguntas, básicamente que el episcopado era sacramento y que el colegio episcopal (que incluye al papa) tiene el poder supremo en la Iglesia. Como la asamblea aprobó el cuestionario mayoritariamente, quedó expedita la dirección (que no la meta) del siguiente periodo de sesiones ${ }^{31}$.

Así pues, tanto la corresponsabilidad genérica laical como la jerárquica episcopal, recibieron un impulso definitivo con el Vaticano II. Para Suenens, además, la corresponsabilidad era imprescindible para el ecumenismo, la otra gran tarea que se impuso el concilio. "Los ortodoxos reprochan a la Iglesia minimizar o suprimir el papel de los obispos; los protestantes, no dar a los laicos el lugar que les corresponde". No podía haber

30 SUENENS, 2000, 162s. "La corresponsabilidad no es reparto de poder sino comunión" (Ibidem 84).

31 El relato en SuENENS, 2000, 143-150. 
acercamiento entre las Iglesias sin avanzar en una eclesiología de comunión. "Es ahí donde se juega su futuro el ecumenismo: es impensable que las Iglesias cristianas no romanas acepten la uniformidad, (...) la unión como absorción"32. Según nuestro cardenal, por tanto, corresponsabilidad y ecumenismo se entraman obligadamente. El papado o su comprensión es uno de los obstáculos mayores en el camino del ecumenismo, lo que incide en la reestructuración colegial de la Iglesia, aparte de la conveniencia en sí de recuperar la tradición comunional más antigua de la Iglesia o de acomodarse mejor a tiempos democráticos. Esto es, tanto por razón ecuménica como por razón teológica y social la corresponsabilidad es irreemplazable. Comunión y ecumenismo, parece susurrarnos, y por la comunión al ecumenismo.

2. El primer anuncio del concilio fue realizado por Juan XXIII un 25 de enero, fiesta de la conversión de san Pablo y conclusión de la semana de oración por la unidad de los cristianos. Desde la convocatoria oficial, y a través de intervenciones posteriores, lo que más repitió fue que lo quería dedicado a la búsqueda de la unión con los otros cristianos ${ }^{33}$. Creó asimismo una comisión preparatoria especial sin paralelo en la Curia, al contrario de las otras comisiones, el Secretariado para la Promoción de la Unidad de los Cristianos. Todo ello será corroborado después solemnemente al comienzo de la Unitatis redintegratio: "Promover la restauración de la unidad entre todos los cristianos es uno de los principales propósitos del concilio ecuménico Vaticano II".

Sería por tanto un concilio ecuménico en sus dos sentidos: el etimológico y tradicional de 'universal' (de oikouméne, 'lo habitado'), dado primeramente al de Nicea por haber reunido a representantes de toda la Iglesia cuyas decisiones valían para todo el Imperio o mundo civilizado; y el más reciente y técnico de 'unitario' -actualizando la idea anterior de universal cristiano-, inventado por los protestantes a finales del siglo XIX al iniciar la tentativa de reconciliación entre las Iglesias ${ }^{34}$. Este esfuerzo ecuménico, rechazado al principio orgullosamente por la Iglesia católica, pues ella estaba en la verdad y eran los otros quienes deberían volver, quedaba por fin asumido oficialmente con el Vaticano II. Significaba que la confrontación confesional contrarreformista había terminado.

\footnotetext{
32 Ibidem 93; 215s.

33 Por ejemplo: AAS 51, 1959, 65-69; AAS 52, 1960, 517-526; AAS 54, 1962, 5-13.

34 Ver J. Bosch, Para comprender el ecumenismo, Estella 1991, 9-12.
} 
Ya la Lumen gentium manifiesta que "la Iglesia se reconoce unida por muchas razones con quienes estando bautizados se honran con el nombre de cristianos, aunque no profesan la fe en su totalidad o no guardan la unidad de comunión bajo el sucesor de Pedro" (LG 15). Y luego enumera dichas razones, empezando por la Escritura y la fe trinitaria, y destacando luego los sacramentos del bautismo y la eucaristía. Sólo estas tres cosas, justamente las vertebraciones de la primera Iglesia, ya nos deberían acercar por encima de cualquier separación. La Trinidad, por ejemplo, compendia la divinidad de Jesucristo, su revelación del Padre como salvación, y la acción de su Espíritu en los creyentes como esperanza e impulso fraterno. Y bautismo y eucaristía son los ritos que remiten más directamente a Jesucristo, enmarcando el comienzo y el final de su misión (Mc 1,9s; 14,22ss), sintetizando el sentido de su salvación: la conversión personal y la entrega a los demás; por tanto los "sacramentos mayores" 35 . Todo lo restante son cuestiones más bien prácticas, de oración litúrgica común y de estructuras necesarias, en las que ciertamente hemos perdido el acuerdo general y no estamos cerca de recuperarlo, pero queda así resaltado que lo que nos une es mucho más importante que lo que nos separa, pues "existe un orden o jerarquía en las verdades de la doctrina católica, ya que es diverso el enlace de tales verdadeś con el fundamento de la fe cristiana" (UR 11). Seguimos siendo "las Iglesias de Cristo" (Rm 16,16), el grupo creyente conformado desde antiguo, la comunión de la fe, la Iglesia seguidora de Jesucristo.

Pero naturalmente, lo que más va a satisfacer a los observadores protestantes será la valoración de la Biblia. Establecer "la Escritura como norma de fe y vida" (LG 15) es toda una declaración de principios, Escritura que supedita el Antiguo al Nuevo Testamento, el Nuevo como criterio axiológico del Antiguo y el Antiguo como premisa gnoseológica del Nuevo, todo ello culminado en la plenitud que es Cristo (DV 14-20). Más allá de cuestiones de detalle, quedarían aquí cicatrizadas las profundas heridas de los tiempos de la Reforma. No hay ya dos fuentes de revelación, sino sólo una: la Palabra de Dios encarnada en Jesucristo; plasmada en la Biblia: la Palabra de Dios escrita; y desplegada en la Tradición: la Palabra de Dios viviente, que no puede contraponerse a la Escritura pues vive en cuanto bebe de ésta. Este realce de la Escritura, teológico, litúrgico y pastoral, resulta altamente significativo para el protestantismo, o más

35 Y. CONGAR, La idea de sacramentos mayores o principales: Concilium 4, 1968, 24 37. 
bien imprescindible, pues para ellos "el problema ecuménico y el problema bíblico se condicionan recíprocamente" 36 . Superada la idea de las dos fuentes de la revelación del tridentino, lamentan alguna frase de $D e i$ Verbum que parece volver literalmente a ello: "ambas se han de recibir y respetar con el mismo espíritu de devoción" (DV 9) ${ }^{37}$, y reprochan que se haya colado el tema al mentar "un único depósito de la Palabra de Dios en la sagrada Tradición y la Sagrada Escritura" (DV 10). En cualquier caso, les encanta que se exprese que la Tradición no significa crecimiento de la revelación sino de su conocimiento (DV 8), y que el Magisterio "no está por encima de la Escritura sino a su servicio" (DV 10). En suma, su constatación gozosa es que por fin en temas cruciales católicos y evangélicos nos hemos aproximado mucho: superando la nivelación Escritura, Tradición y Magisterio en favor de la Escritura.

La Unitatis redintegratio será la Carta Magna del ecumenismo católico. En ella, ortodoxos y protestantes ya no serán vilipendiados como cismáticos y herejes, sino vistos como "hermanos separados" (UR 3), y las instituciones cristianas a que han dado lugar no son desviaciones, sino "Iglesias" y "comunidades eclesiales" (LG 15). Esta diferencia denominativa no quiere ser ningún desdoro: de un lado, se constata la asimétrica ruptura con unos u otros según hayan conservado o no la sucesión apostólica; de otro, la tradición comunitaria protestante no se reconoce tanto en una institucionalidad fuerte (o Iglesia) cuanto en una cohesión carismática (o comunión eclesial). De todos modos, "una sola es la Iglesia fundada por Cristo" (UR 1), la comunión de los que le siguen como Señor, que por tanto no puede identificarse simplemente (est) con la Iglesia católica, aunque permanezca (subsistit) en ella (LG 8; UR 4). El paso del est del esquema inicial al subsistit del texto final, contra su ambigüedad semántica y los líos hermenéuticos que ha generado, es una fórmula conciliadora, ecuménica, que corrige la identificación anterior entre la Iglesia católica y el Cuerpo místico de Cristo que había consignado la Mystici corporis de Pío XII (1943). A pesar de congratularse y alabar el nuevo clima, Barth deplora de todos modos que no se haya reconocido expresamente que la iniciativa ecuménica partió del protestantismo ${ }^{38}$, habiendo

36 CullmanN, 1967, 162. Lo mismo Barth 27;37. Aunque deploran que no se afirme expresamente que Tradición y Magisterio están sometidos a la Escritura, reconocen en la Iglesia católica "una sumisión práctica a la Biblia" (CullmanN, 1967, 153), que defiende respecto a aquéllos "si no el dominio, sí el predominio de la Sagrada Escritura" (BARTH 78).

37 Ver para Trento DENZINGER - HÜNERMANN 1501.

38 BARTH 45. 
sido tan difíciles los comienzos y resultando ahora tan apreciado y vistoso. Al César lo que es del César, nos viene a decir.

\section{Iglesia es evangelio}

Cuando al poco de acabar el Vaticano II solicitaron a Rahner que resumiese el legado más importante que nos dejaba el concilio, respondió que comparando el antes y el después del evento la Iglesia había pasado de "una postura negativa y defensiva a una actitud más abierta y positiva hacia el mundo", plasmada en la acogida de la cultura moderna, de su organización social, y de su ciencia y técnica. Sintetizará luego que todo ello puede considerarse "el fin de la época piana" 39 , o sea, los pontificados de Pío IX (1846-1878) y Pío XII (1939-1957), que podemos redondear situándolos entre la segunda mitad del siglo XIX y la primera mitad del siglo XX, queriendo señalar, por tanto, que supone el fin de la contramodernidad.

Modernidad, Edad Moderna, el nombre puede ser tan impropio como llamar medieval o Edad Media a lo que hace de puente entre la Antigüedad (que es moderna respecto a la prehistoria y medieval entre Edad Antigua y Medievo) y su revitalización en el Renacimiento. Pero son convenciones muy expresivas, útiles para entendernos. Las características troncales de la Modernidad, en ruptura con el Medievo, serían el humanismo o centralidad de lo humano (el individuo, el mundo) y la ciencia experimental. Así, la Reforma protestante resalta la conciencia personal como criterio salvífico, más allá de cualquier otra institución eclesial (jerarquía, tradiciones), y el método probativo de Galileo subvierte el saber metafísico anterior (geocentrismo, perfección astral). Todo ello va a implicar un alejamiento progresivo entre la sociedad y la Iglesia, cuya cima se encontrará en el racionalismo ilustrado (que disuelve la fe como superchería) y la emancipación de los Estados decimonónicos (que arrinconan el poder de la Iglesia). El Magisterio eclesial recogió el guante y desautorizó cuanto se le presentó como innovación vanguardista: el Syllabus complectens praecipuos nostrae aetatis errores de Pío IX (1864), sumario de los principales errores epocales, como la libertad de conciencia y pensamiento, el relativismo racionalista y moral, la separación entre Estado e Iglesia, la supresión del poder temporal eclesial... que rechazaba en su conjunto el progreso como enemigo declarado 40 .

\footnotetext{
39 P. IMHOF - H. Biallowons, Karl Rahner im Gespräch, I. 1964-1977, München 1982, $92 ; 291$.

40 DENZINGER - HÜNERMANN 2901ss.
} 
El Vaticano II ha supuesto el final de esta agria contraposición de la Iglesia respecto del mundo y recogido los valores de la Modernidad. Todo lo que el Syllabus denostaba, que debe ser entendido en el contexto de la lucha entre Iglesia y Estado, es un siglo después aceptado en una nueva situación de colaboración y diálogo entre los otrora contendientes. La constitución Gaudium et spes da prueba de ello ofreciendo un repaso respetuoso por las características de la cultura moderna, en la que entre otras cosas se alaba la libertad y la democracia (GS 73), y se acepta la autonomía de la sociedad respecto a la Iglesia (GS 36). Igualmente pasa con la Dignitatis humanae al hacer de la libertad de culto y conciencia una de las señas distintivas de la renovación eclesial (DH 2). También, aunque más indirectamente, se ensalza el progreso científico y técnico de nuestro tiempo (GS 44), y hasta se admiten los modernos estudios científicos de la Sagrada Escritura, que insertan a cada hagiógrafo en su época y analizan sus fuentes y destinatarios para exponer (exegeísthai, 'explicar') lo que quiso decir, "la intención del autor", y así interpretar (hermeneúein, 'traducir') su aplicación actual, "la analogía de la fe" (DV 12), superando arbitrariedades y literalidades. Por ejemplo, si Pablo dice que la mujer debe llevar el velo en el culto (1Cor 11,2ss), podemos deducir que lo requirió como signo de unión de los nuevos cristiano-gentiles con los primeros cristiano-judíos $(11,16)$, y en vez de seguirlo literalmente (fundamentalismo) mantener con sencillez su idea de cohesión eclesial, para lo que ni falta que hace el velo femenino. Al fin y al cabo, "la letra mata mientras el espíritu vivifica" (2Cor 3,6).

La Iglesia no puede ser de ningún modo contraposición al universo sino todo lo contrario: dedicación a él, "luz del mundo, sal de la tierra" (Mt $5,13 \mathrm{~s})$. Su actitud, de modo incondicional, tendrá que ser benevolente, salvífica, evangélica. La Iglesia ha nacido del evangelio: es como la coagulación de la efervescencia surgida con la persona de Jesucristo. Y sólo se justifica desde el evangelio: existe para perpetuar su mensaje, la revelación de Dios, para llevarlo a todo lugar y sostenerlo en la historia. La Iglesia es evangelio, está constituida por y para el anuncio evangélico. Ahora bien, evangelio, como la propia palabra significa, es 'buena noticia', anuncio de la salvación. De manera que la Iglesia debe ser esfuerzo y disposición para presentar en todas partes la alegría de la gracia, debe ser trasmisora constante de la misericordia divina. En caso contrario no estará cumpliendo su deber, sino tergiversando la razón de su existencia. Esto no quiere decir que deba tragar ruedas de molino, transigir con inhumanidades o injusticias, hacer la vista gorda a rebajas de la dignidad de los hijos de Dios; sino que su tarea es primeramente curativa, portadora de esperanza, instru- 
mento de la salvación ${ }^{41}$. Al revés de aquel entrenador extranjero de fútbol: 'tú nunca negatifa, siempre positifa'.

La misión, ese impulso tan característico del cristianismo -ninguna otra religión lo ha sentido igualmente- brota de la lógica del evangelio: si no hay más que un Dios y éste es Padre compasivo, esta buena noticia debe trasladarse a todos sus hijos tanto por obligación como por devoción: "predicar el evangelio es un deber que me incumbe" (1Cor 9,16), de un lado; "gratis lo recibisteis, dadlo gratis" (Mt 10,8), de otro. Así lo han entendido los cristianos desde el primer momento, tanto de modo orgánico como individual: sus ministros más reverenciados fueron los apóstoloi, 'misioneros' (1Cor 12,28); pero todos se supieron obligados al testimonio personal, eran un "sacerdocio real para anunciar las alabanzas" de Dios (1Pe 2,5). Con ello no hacían sino seguir al Maestro, que "recorría todas las ciudades y aldeas enseñando en sus sinagogas y proclamando la Buena Nueva del reino" (Mt 9,35); y que tras la resurrección había pedido: "Id por todo el mundo y proclamad la Buena Nueva a toda la creación" (Mt 16,15). La misión tiene pues una vertiente colectiva (crear instituciones eclesiales: parroquias, conventos, beneficencia...) y otra individual (reflejar existencialmente los valores cristianos: esperanza ante la muerte, fraternidad ante el mal...). Ambas se complementan, podríamos decir que el testimonio es la misión individual como la misión es el testimonio eclesial. Por eso expresa el concilio que "la Iglesia es esencialmente misionera" (AG 2), que misión e Iglesia son conceptos coincidentes. Naturalmente, siguiendo el principio de la libertad religiosa, la misión no es conquista o proselitismo, sino "diálogo interreligioso" (NA 2).

Rahner pronostica la constitución Lumen gentium como "el resultado más importante del concilio" 42 , y lo que destaca de dicho documento es que la Iglesia ya no se opone al mundo, sino todo lo contrario, es para él "como un sacramento, o sea, signo e instrumento de la unión íntima con Dios y de la unidad de todo el género humano" (LG 1). La teología cristiana ha ido elaborando durante más de un milenio, de san Agustín al concilio de Trento, la noción de los sacramentos como ritos especiales, "signos sagrados que contienen y confieren la gracia que significan" 43 . Es decir, en

41 Es un alivio y estímulo constatar que por ahí se encamina la renovación del papado actual (A. SPADARO, Intervista a papa Francesco: La Civiltà Cattolica 164, 2013, 449-477).

42 Doctrina conciliar de la Iglesia y realidad futura de la vida cristiana: Escritos de Teología, VI, Madrid 1969, 469.

43 DENZINGER - HÜNERMANN 1606. 
cuanto sacramentos no solamente muestran, son signo de la salvación de Dios, sino que la actúan, son su instrumento en la fe del creyente. Por tanto, los sacramentos son signos eficaces de gracia. La Iglesia sería así "como un sacramento", refleja o contiene el amor de Dios ejemplificado en Cristo, y de este modo lo trasmite o confiere, "es sacramento universal de salvación". (LG 48; SC 45; AG 1). No habría que entender el "fuera de la Iglesia no hay salvación" en un sentido literal y excluyente, por lo demás minoritario en la tradición cristiana ${ }^{44}$, sino en el hiperbólico y metafórico de que la Iglesia debe ser sobre todo salvación, "perceptibilidad histórica de la gracia en la que Dios se autocomunica en cercanía y perdón absolutos" 45 .

Abogará así por "una salvación universal, un optimismo que forma parte de la necedad de la cruz, a la que nos debemos como mensajeros de la esperanza de Dios contra la desesperanza del hombre"46. La voluntad salvífica universal de Dios ha sido una clara noción neotestamentaria $(1 \operatorname{Tm} 2,4)$, y aunque postergada continuamente en la historia con las amenazas del infierno, nos ha sido venturosamente recuperada con el concilio. Lumen gentium recalca esta voluntad salvífica universal de Dios (LG 9; $13 ; 17)$, que asume a los creyentes de religiones no cristianas e incluso "a los que buscan a Dios con un corazón sincero" y a los no creyentes que "se esfuerzan en llevar una vida recta" (LG 16). E igualmente hacen otros documentos respecto de las religiones no cristianas (AG 3; NA 2). Sobre Nostra aetate y su valoración del judaísmo e islamismo, Barth se pregunta si no hubiera sido bueno un expreso reconocimiento de culpas por parte de la Iglesia, teniendo en cuenta la enemistad pasada; y lo mismo aplica a Dignitatis humanae, que basa la libertad religiosa en la dignidad de la persona, dados sus siglos de connivencia con la coacción estatal ${ }^{47}$.

44 Y. CongAR, Santa Iglesia, Barcelona 1965, 367-381.

45 RAHNER VI, 473s. También: "si fuera preciso resumir en una sola fórmula la intención de conjunto del Vaticano II, diríamos que la Iglesia ha querido ser para el mundo, y para el mundo tal como es hoy" (Y. CONGAR, Iglesia y mundo en la perspectiva del Vaticano II: Y. Congar - M. Peuchmaurd (eds), La Iglesia en el mundo de hoy. Constitución pastoral Gaudium et spes, III, Madrid 1970, 33).

46 P IMHOF - H. Biallowons, La fe en tiempo de invierno. Diálogos con Karl Rahner en los últimos años de su vida, Bilbao 1989, 150.

47 BARTH $58 ; 61$. 


\section{CONCLUSIONES}

Con el concilio "íbamos a vivir el final de una época, heredera de un largo pasado: de Constantino (siglo IV) al concilio de Trento (siglo XVI) y de Trento al Vaticano I (siglo XIX)"48. Las esencias del Vaticano II, siguiendo a los maestros del siglo $\mathrm{XX}$, parecen condensarse en corregir errores garrafales de la Iglesia acumulados a lo largo de su historia como una bola de nieve pendiente abajo. Punto final del constantinismo, final de la contrarreforma, final de la contramodernidad. El acopio de poder social y espiritual ha degenerado en prepotencia e intolerancia, ha llevado a la imposición de la fe, una manifiesta contraditio in terminis, como si se pudiera obligar a la confianza. Con la Reforma, el furor de la polémica ha ido arrasando también las bondades ajenas (primacía de la Escritura y la conciencia) derivando en fuerte clericalismo y partidismo confesional, haciendo que la Iglesia dependiese sólo de sus instituciones jerárquicas, negligiendo al común de los creyentes. Y el choque violento con los Estados laicistas y democráticos ha barrido ciegamente todo el progreso social decimonónico, como si cristianismo y humanismo no tuviesen nada que ver.

El revés de esta trama conciliar, o más bien el derecho de su tejido y la nitidez de los bordados, viene a destacar que sólo hay fe auténtica desde la decisión libre e íntima, que la estructura eclesial se construye desde la corresponsabilidad de las personas creyentes, que la Iglesia sólo sirve siendo una leal y humilde trasmisora de la salvación de Dios. Fe es libertad, Iglesia es comunión, Iglesia es evangelio. Visto así, el Vaticano II es en realidad una vuelta al origen del cristianismo, a los fundamentos de la Iglesia. Rahner lo expresa inmejorablemente cuando dice que el concilio es "el comienzo del comienzo" 49 , como volver a empezar tras un desvío de siglos y un desvarío de ideas. Nunca es tarde si la dicha es buena.

Que la fe es libertad es un don impagable del concilio. Sin apoyo de los poderes públicos (aunque igualmente sin impedimentos), construida únicamente sobre sus creencias, tejerá una Iglesia de conciencia y no de masas, de celebración convencida y no sociológica, de testimonio diario y no cumplimiento externo. Habría que agradecer, más que lamentar, esta fe minoritaria pero sincera, cambiar "un cristianismo sociológico por otro

48 SUENENS, 2000, 82.

49 K. RAHNER, El concilio, nuevo comienzo: K. Lehmann (y otros), Karl Rahner. La actualidad de su pensamiento, Barcelona 2004, 76. Congar rementa que el Vaticano II es más recuperación que innovación de ideas (MADRIGAL, 2005, 23). 
más personal"50. Parece que el problema se ha localizado en la Gaudium et spes, que en su ingenuo optimismo promovería la mundanización de la Iglesia. De un lado estarían Chenu, Congar, Rahner, Suenens, que no temen ninguna disolución eclesial en el mundo. Del otro, se escoran Ratzinger y De Lubac, escoltados por Cullmann y Barth, que quieren destacar la alteridad irreductible del evangelio respecto al mundo. En el segundo caso, la fe en la verdad revelada pareciera implicar la obligación (subjetiva, no institucional) de imponerlo. A saber cómo se come eso. En realidad, el empequeñecimiento de la Iglesia es necesario, derivado de la fe como libertad. Los riesgos de la libertad tienen la cruz del relativismo y el error, pero esta moneda conlleva la cara de la convicción y la decisión personales, condiciones de la fe veraz. Las consecuencias de la libertad son la tolerancia y el pluralismo, que en absoluto son un mal sino más bien las virtudes de un mundo autónomo, a las que solo recientemente hemos podido acceder..

La Iglesia es comunión, el compromiso de todos los creyentes en su edificación, que no se basará primeramente en una milimétrica estructura, en la detallada funcionalidad del andamiaje canónico, sino sobre todo en el testimonio diario y corriente reflejado en la vida de los fieles. Ser cristiano es una mentalidad, un modo de entender la vida y vivirla, y de este modo trasmitirla. La Iglesia existirá mientras haya fe auténtica, más allá de una mejor o peor organización, de instituciones más o menos eficaces. Barth cree que mediante la concentración cristológica de la fe, se rebajará la importancia que la Iglesia institucional pueda darse a sí misma, avanzando en la estima del laicado y relativizando el clericalismo. Hay que asociar más a los seglares al apostolado común de la Iglesia, pues no hay un apostolado jerárquico especial sino una tarea conjunta de testimonio, algo inherente al ser cristiano 51 .

Ecuménicamente, aun entusiasmado por el impulso del concilio, Cullmann no deja de percibir que es una renovación "a la católica", limitada, manteniendo los dogmas y la tradición que constituyen la esencia del catolicismo. Según él, el truco ha seguidos dos patrones: yuxtaponer al dogma antiguo la concepción moderna (por ejemplo, primado papal y colegialidad episcopal), de modo que ésta dulcifique el rigor de aquél; y

50 SUENENS, 2000, 163. Lo había teorizado previamente Rahner (Cambio estructural en la Iglesia, Madrid 1974).

51 BARTH 32; 48ss citando AA 27 (commune testimonii officium) y AG 2 ("Ia Iglesia es esencialmente misionera"). 
reclasificar los dogmas por orden de importancia siguiendo el principio de la "jerarquía de verdades" (por ejemplo, anteponiendo la Trinidad a la Asunción). No lo expresa en absoluto como crítica, sino dentro del reconocimiento de los carismas confesionales: si el protestantismo resalta la Escritura, el catolicismo le aúna Tradición y Magisterio. Para él, "el ecumenismo no debe caminar en sentido de una fusión, sino de una federación"52.

Finalmente (tal vez únicamente), la Iglesia es evangelio: buena nueva salvífica, proclamación de esperanza, afirmación de sentido... Y desde ahí es conversión: llamada a la fraternidad, esfuerzo de generosidad, "combate por la justicia”, búsqueda de la paz... Una Iglesia evangélica se concibe como favorable al mundo, a quien incondicionalmente debe anunciar la buena noticia. No es aceptar toda la evolución social, sino que en todo caso su tarea es trasladar la esperanza del amor de Dios. Una Iglesia evangélica será una Iglesia "esencialmente misionera" 53 , pues "el evangelio es una fuerza de Dios para la salvación de todo el que cree" $(\mathrm{Rm} 1,16)$. Misionera no porque en todas partes pretenda construir templos y tener obispos, sino porque en todas partes, a través de los creyentes, vive y trasmite su fe. Sinónimo de Iglesia misionera no será el de Iglesia viajera al extranjero, generalmente subdesarrollado, sino el de comunidad testimonial. La misión eclesial es su vida cotidiana desde los valores cristianos, compendiados como la esperanza en Dios salvador y el compromiso por la fraternidad. Por eso la Iglesia es siempre misionera y el mundo es su misión, constantemente debe ser testigo de la Palabra divina y dondequiera que esté dejar su sustrato espiritual, "dando razón de su esperanza" (1Pe 3,15).

52 Habla de ello en CullmanN, 1971, 12ss; la cita en 44.

53 La expresión de AG 2 está ya en Y. CoNGAR, Una, santa, católica y apostólica: VV AA, Un concilio para nuestro tiempo, Barcelona 1962, 164. 
